\title{
Grand challenges in pharmacotherapy of inflammation for the first decades of the 21st century
}

\section{Paola Patrignani*, Stefania Tacconelli and Annalisa Bruno}

Department of Medicine and Center of Excellence on Aging, "G. d'Annunzio" University, School of Medicine, Chieti, Italy ${ }^{*}$ Correspondence: ppatrignani@unich.it

Inflammation is a complex set of interactions among soluble factors and cells that can arise in any tissue in response to traumatic, infectious, postischemic, toxic or autoimmune injury (Nathan, 2002; Gilroy et al., 2004). Inflammation, per se, does not cause disease. But unchecked inflammation that spreads possibly due to disruption of the resolution processes can lead to chronic persistent inflammation which plays a role in the progression of many diseases, such as atherosclerosis, asthma, neurodegeneration, inflammatory bowel diseases (IBDs) and cancer. Thus, inflammation is one of the relevant areas in biomedical research. Molecular mechanisms regulating the checkpoints tuning on and off the inflammatory response have been revealed and numerous novel potential therapeutic targets have been uncovered. Humanized antibodies for anti-cytokine therapy have been shown to be effective for the treatment of rheumatoid arthritis and various inflammatory diseases (Maini and Taylor, 2000). However, there is still an important gap to be filled by developing new therapeutics which should be safer and more specific for different inflammationrelated diseases.

Importantly, we need to dissect the influence of genetic background but also behavioral and psychosocial factors in different socioeconomic groups on increased susceptibility to inflammation. This knowledge will lead to predict and prevent inflammatory-related diseases and hopefully to reduce social inequalities in disease development observed in many populations (Ranjit et al., 2007).

\section{DEVELOPMENT OF STRATEGIES TO IMPLEMENT PERSONALIZED MEDICINE OF ANTI-INFLAMMATORY DRUGS}

Since the development of inflammatoryrelated diseases is a complex multi-step process involving many biological pathways as well as environmental factors, it will be possible to identify molecular fingerprints, of multiple genes, RNAs, proteins, metabolites, or combination of them, associated with unchecked inflammation. The ultimate goal of the genomic, proteomic, and metabolomic studies will be to clarify whether changes in the interconnecting networks of genes, proteins, and metabolites are involved in disease susceptibility and/or accelerated disease progression. These studies will lead to the discovery of novel disease biomarkers which will be very useful to improve clinical interventions and to translate into personalized strategies of treatment (FitzGerald, 2005). Thus, it will be possible to tailor commercialized medicines or novel therapeutics to the individual patient, minimizing the number of exposed individuals who fail to benefit from the treatment or experience adverse events from the treatment.

\section{INTEGRATION OF REGENERATIVE MEDICINE INTO INFLAMMATION RESEARCH}

A difficult, but possible, challenge of inflammatory research is to regenerate the impaired organs due to excessive chronic inflammation. In osteoarthritis and other degenerative diseases of the bones and joints, it will be possible to regenerate the damaged tissue by using patient's stem cells. However, many obstacles persist, such as a suboptimal frequency and abundance of adult stem cells, or limited potency. Importantly, the environment plays an active role in promoting growth and potency of stem cells (Logan et al., 2007). The environment within the body changes hugely as you age and this represents a factor which limits stem cell maintenance. However, it is possible to modify stem cells in the lab and re-introduce them to the body. Recent findings have shown that modified adult stem cells through the introduction of cyclic AMP which activates protein kinase A (PKA), maturate into bone cells when reintroduced to the body (Siddappa et al., 2008).

\section{NOVEL INSIGHTS INTO CHRONIC INFLAMMATION AND CANCER DEVELOPMENT AND PROGRESSION}

The association of chronic inflammation and cancer development and progression is becoming apparent but the mechanisms remain largely obscure. Thus, IBDs, both ulcerative colitis (UC) and Crohn's colitis, ranks among the top three high-risk conditions for colorectal cancer (CRC), together with the hereditary syndromes of familial adenomatous polyposis (FAP) and hereditary nonpolyposis colorectal cancer (HNPCC) (Itzkowitz and Yio, 2004). Unlike the latter two conditions that have a well-defined genetic etiology, CRC risk in IBDs appears to be related more to chronic inflammation of the gastrointestinal (GI) mucosa triggered in a susceptible individual by an environmental insult such as GI infection or other environmental toxins (Itzkowitz and Yio, 2004). Recent studies have underscored a striking connection between tissue injury, repair and malignancy and systemic rheumatic diseases (Rosen and Casciola-Rosen, 2006).

A new hypothesis is that chronic inflammation may switch on the endogenous injury-repair machinery where stem cells play a critical role. It is possible that increased stem cell recruitment and mutation in the environment of chronic inflammation may translate into cancer formation in the inflamed target tissue (Houghton et al., 2004). Prostaglandin $\mathrm{E}_{2}\left(\mathrm{PGE}_{2}\right)$, an important mediator of inflammation which has been shown to induce somatic and embryonic cell survival (North et al., 2007), might be the link among inflammation, stem cells and cancer development.

In addition to this mechanism, $\mathrm{PGE}_{2}$ promotes cancer development by multiple other effects, ie by inhibiting apoptosis, 
promoting cell growth, inducing angiogenesis and tumor invasion (Wang and Dubois, 2006). Altogether these findings suggest that inhibition of inflammatory $\mathrm{PGE}_{2}$ may be an appropriate strategy to fight cancer (Cha and DuBois, 2007).

$\mathrm{PGE}_{2}$ is generated from arachidonic acid (AA) after its release from membrane phospholipids by phospholipases. AA is transformed into prostaglandin (PG) $\mathrm{H}_{2}$, through the activity of cyclooxygenase (COX) enzymes (i.e. COX-1 and COX-2) (Funk, 2001). The isomerization of $\mathrm{PGH}_{2}$ to $\mathrm{PGE}_{2}$ is catalyzed by three different isomerases: $\mathrm{a}$ cytosolic PGE synthase (cPGES) and two membrane-bound PGESs, mPGES-1 and mPGES-2. (Kudo and Murakami, 2005). Of these isomerases, cPGES and mPGES-2 are constitutive enzymes whereas mPGES-1 is mainly an induced isoform. $\mathrm{PGE}_{2}$ interacts with specific receptors, termed EP1-4, that have restricted patterns of expression and receptor-specific actions (Narumiya and FitzGerald, 2001; Kamei et al., 2003).

Inhibition of COX-2-dependent $\mathrm{PGE}_{2}$ by nonsteroidal anti-inflammatory drugs (NSAIDs) selective for COX-2 (coxibs) has shown to have chemopreventive activity for CRC and other types of cancer (Thun et al., 2002; Cha and DuBois, 2007). However, the long-term use of coxibs is restricted by the occurrence of adverse cardiovascular events believed to be associated with the reduction of the biosynthesis of vascular COX-2-dependent prostacyclin which is an important protective pathway for the cardiovascular system (Grosser et al., 2006; García Rodríguez et al., 2008; Patrignani et al., 2008). A possible strategy to overcome the cardiovascular toxicity of COX-2 inhibition is to target the downstream enzyme in $\mathrm{PGE}_{2}$ biosynthesis, ie mPGES-1. In fact, several evidences suggest a key role of $\mathrm{mPG}$ ES-1 in carcinogenesis (Kamei et al., 2003; Hanaka et al., 2009).

\section{DEVELOPMENT OF mPGES-1 INHIBITORS AS NOVEL ANTI- INFLAMMATORY AGENTS}

Inhibitors of mPGES-1 are in preclinical development for relief of pain - similarly to NSAIDs - (Bruno et al., 2010; Koeberle et al., 2010) but with the potential advantage of not affecting or perhaps causing a beneficial impact on the cardiovascular system (Wang et al., 2006, 2008). In fact, deletion of mPGES-1 in mice is associated with a profound inhibition of $\mathrm{PGE}_{2}$ in vitro and in vivo and with a redirection of the $\mathrm{PGH}_{2}$ substrate to other PG synthases, such as $\mathrm{PGI}_{2}$ and $\mathrm{PGD}_{2}$, which might participate to the safe cardiovascular profile (Wang et al., 2006, 2008). Inhibitors of mPGES-1 might circumvent adverse GI side effects of unselective COX inhibitors. However, in the stomachs of mice lacking mPGES-1, a shift from $\mathrm{PGE}_{2}$ to all other prostanoids, i.e. $\mathrm{TXA}_{2}, \mathrm{PGD}_{2}, \mathrm{PGF}_{2 \alpha}$, and $\mathrm{PGI}_{2}$, was detected, thus making extremely difficult to predict the clinical consequences of mPGES-1 inhibition in the GI tract (Boulet et al., 2004). Further studies addressing this issue in appropriate animal models are required.

\section{DEVELOPMENT OF DUAL INHIBITORS OF mPGES-1 AND 5-L0}

$\mathrm{PGE}_{2}$ couples via high-affinity EP4 receptors and may upregulate IL-8 (Yu and Chadee, 1998). IL-8 is a potent chemokine which can attract and activate neutrophils to cause nonspecific tissue damage, important in the onset of colonic inflammation (Dey et al., 2006). Activated leukocytes alone and their interaction with other cells, mainly with platelets, via P-selectin/P-selectin glycoprotein ligand-1 (PSGL-1), are involved in enhanced generation of leukotrienes (LT) (Evangelista et al., 1999). LTs, ie LTB $_{4}$ and $\mathrm{LTC}_{4}$, are important factors of inflammatory responses. They are produced from AA by 5-lipoxygenase (5-LO), functionally coupled to 5-LO-activating protein, an integral membrane protein present on the nuclear envelope that presents AA to 5-LO. Neutrophils generate the unstable intermediate $\mathrm{LTA}_{4}$ by 5 -LO; then, it is released or enzymatically hydrolyzed by LTA $_{4}$ hydrolase to produce $\mathrm{LTB}_{4}$. When released, $\mathrm{LTA}_{4}$ can be taken up by neighboring cells, in particular platelets, and conjugated with glutathione by $\mathrm{LTC}_{4}$ synthase to generate $\mathrm{LTC}_{4}$ that is further metabolized extracellularly to $\mathrm{LTD}_{4}$ and LTE $_{4}$ (Gijón et al., 2007). Altogether these findings support an important cooperation of COX-2/mPGES-1 and 5-LO pathways in inflammatory diseases. The development of dual inhibitors of mPGES-1 and 5-LO pathways may represent a novel strategy to restrain inflammation (Koeberle et al., 2008, 2010). There is accumulating evidence that inhibition of both the LT and the PG biosynthetic pathway is superior over single interference, in terms of anti-inflammatory effectiveness and also due to a lower incidence of gastrointestinal toxicity (Celotti and Laufer, 2001; Kulkarni and Singh, 2007).

Interestingly, the pro-infiammatory 5 -LO product $\mathrm{LTD}_{4}$ is tumorigenic causing translocation of $\beta$-catenin both to the mitochondria, in which it associates with the survival protein $\mathrm{Bcl}-2$, and to the nucleus in which it activates the TCF/LEF transcription machinery involved in the expression of pro-tumorigenic genes, ie $C O X-2, c-m y c$, cyclin D1, and PPAR $\delta$ (Mezhybovska et al., 2006). Moreover, it has been recently shown that 5-LO gene (Alox5) may represent a novel strategy to target cancer stem cells. Loss of the Alox5 gene impairs leukemia stem cells and prevents chronic myeloid leukemia in experimental animals (Chen et al., 2009).

\section{MICRORNAs AS THERAPEUTIC TARGETS}

MicroRNAs (miRNAs) are an emerging class of highly conserved, non-coding small RNAs that regulate gene expression on the post-transcriptional level by inhibiting the translation of protein from mRNA or by promoting the degradation of mRNA (Czech, 2006).

More than 800 miRNAs have been identified in mammals and increasing evidence indicates that miRNAs have distinct expression profiles and play crucial roles in various physiological and pathological processes such as cardiogenesis, haematopoietic lineage differentiation, oncogenesis, vascular disease and inflammation. miRNAs are thought to control up to $30 \%$ of all gene activity, with one type responsible for directing the expression of whole networks of genes, rather than just single genes. Several lines of evidence show that miRNAs play a key role in checking inflammation. Thus, miR146 has been proposed to target the 3' UTRs (untranslated regions) of the TRAF6 and IRAK-1 genes, and to control Toll-like receptor and cytokine signaling through a negative feedback loop, thus reducing inflammatory cytokines production (Taganov et al., 2006). In mature human dendritic cells, miR-155 has been shown to be part of a negative feedback loop, which down-modulates inflammatory cytokine production in response to microbial stimuli (Ceppi et al., 2009). Moreover, miR-16, has been shown to contribute to AU-rich element-mediated mRNA turnover of inflammatory genes, such as TNF- $\alpha$, IL-6, 
and COX-2 by facilitating degradation of these transcripts (Jing et al., 2005). Thus, the identification of the actions of microRNAs adds new layers of complexity to our understanding of inflammation.

There is a great interest to develop miRNA-inhibiting drugs. Single-stranded RNA molecules have been designed to bind specifically to miR-122, which is thought to regulate up to 450 genes, around 100 of which are involved in cholesterol and lipid metabolism. This miRNA inhibitor, or antimiR, is readily taken up by liver cells and lowers cholesterol by up to 35\% (Esau et al., 2006).

\section{NEW ERA OF PHARMACOVIGILANCE}

Effective use of medicines requires balancing the benefits and risks. No effective medicine is without risk. Most of these risks are known when a product is launched; however, some of the risks are unknown and are discovered during clinical use. In fact, pre-marketing findings regarding safety of medicines are commonly based on the experience of hundred to a maximum of a few thousand people, who have been treated in controlled randomised trials. Thus, they are too small to detect very rare events, used selected "healthy" populations and often too short to detect long-term effects. Thus, post-marketing pharmacovigilance acts an important role in patient safety. The application of pharmacoepidemiological methods together with the use of pharmacogenomics tools (Arehart et al., 2008) will open the way to a new era of pharmacovigilance (García Rodríguez et al., 2008; Massó González et al., 2010). This will allow to put information out on drug hazard as quickly as possible and to make appropriate decisions on risk management.

\section{CONCLUSIONS}

Several stimulating challenges in pharmacotherapy of inflammation will be addressed in the 21 st century. Understanding in detail the role played by stem cells in inflammatory-related diseases will lead to the development of innovative therapeutic strategies. Moreover, the development of new therapeutic tools by targeting miRNAs has enormous potential. However, it is wise to improve our knowledge on how the miRNA regulatory system works before developing miRNA inhibitors. In fact, a
miRNA may control whole groups of genes and its inhibition could be associated with unforeseen side effects.

There is the need of safer anti-inflammatory agents in association with the development of valid biomarkers of efficacy and toxicity to tailor drug treatment to individual characteristics. This will be promoted by the availability of sophisticated technologies to detect changes in the interconnecting networks of genes, proteins, and metabolites which may be involved in disease susceptibility and/or accelerated disease progression and drug responses. The application of pharmacoepidemiological methods together with the use of pharmacogenomics tools will open the way to a new era of pharmacovigilance to put information out on drug hazard as quickly as possible and to make appropriate decisions on risk management.

\section{REFERENCES}

Arehart, E., Stitham, J., Asselbergs, F. W., Douville, K., MacKenzie, T., Fetalvero, K. M., Gleim, S., Kasza, Z., Rao, Y., Martel, L., Segel, S., Robb, J., Kaplan, A., Simons, M., Powell, R. J., Moore, J. H., Rimm, E. B., Martin, K. A., and Hwa, J. (2008). Acceleration of cardiovascular disease by a dysfunctional prostacyclin receptor mutation: potential implications for cyclooxygenase-2 inhibition. Circ. Res. 102, 986-993.

Boulet, L., Ouellet, M., Bateman, K. P., Ethier, D., Percival, M. D., Riendeau, D., Mancini, J. A., and Méthot, N. (2004). Deletion of microsomal prostaglandin E2 (PGE2) synthase-1 reduces inducible and basal PGE2 production and alters the gastric prostanoid profile. J. Biol. Chem. 279, 23229-23237.

Bruno, A., Di Francesco, L., Coletta, I., Mangano, G., Alisi, M. A., Polenzani, L., Milanese, C., Anzellotti, P., Ricciotti, E., Dovizio, M., Di Francesco, A., Tacconelli, S., Capone, M. L., and Patrignani, P. (2010). Effects of AF3442 [N-(9-ethyl-9H-carbazol-3-yl)-2(trifluoromethyl)benzamide], a novel inhibitor of human microsomal prostaglandin E synthase-1, on prostanoid biosynthesis in human monocytes in vitro. Biochem. Pharmacol. 79, 974-1081.

Celotti, F., and Laufer, S. (2001). Anti-inflammatory drugs: new multitarget compounds to face an old problem. The dual inhibition concept. Pharmacol. Res. 43, 429-436.

Ceppi, M., Pereira, P. M., Dunand-Sauthier, I., Barras, E., Reith, W., Santos, M. A., and Pierre, P. (2009). MicroRNA-155 modulates the interleukin-1 signaling pathway in activated human monocyte-derived dendritic cells. Proc. Natl. Acad. Sci. U.S.A. 106, 2735-2740.

Cha, Y. I., and DuBois, R. N. (2007). NSAIDs and cancer prevention: targets downstream of COX-2.Annu. Rev. Med. 58, 239-252.

Chen, Y., Hu, Y., Zhang, H., Peng, C., and Li, S. (2009). Loss of the Alox5 gene impairs leukemia stem cells and prevents chronic myeloid leukemia. Nat. Genet. 41, 783-792.

Czech, M. P. (2006). MicroRNAs as therapeutic targets. N. Engl. J. Med. 354, 1194-1195.
Dey, I., Lejeune, M., and Chadee, K. (2006). Prostaglandin E2 receptor distribution and function in the gastrointestinal tract. Br. J. Pharmacol. 149,611-623.

Esau, C., Davis, S., Murray, S. F., Yu, X. X., Pandey, S. K., Pear, M., Watts, L., Booten, S. L., Graham, M., McKay, R., Subramaniam, A., Propp, S., Lollo, B. A., Freier, S., Bennett, C. F., Bhanot, S., and Monia, B. P. (2006). miR-122 regulation of lipid metabolism revealed by in vivo antisense targeting. Cell Metab. 3, 87-98.

Evangelista, V., Manarini, S., Sideri, R., Rotondo, S., Martelli, N., Piccoli, A., Totani, L., Piccardoni, P., Vestweber, D., de Gaetano, G., and Cerletti, C. (1999). Platelet/polymorphonuclear leukocyte interaction: P-selectin triggers protein-tyrosine phosphorylationdependent CD11b/CD18 adhesion: role of PSGL-1 as a signaling molecule. Blood 93, 876-885.

FitzGerald, G.A. (2005). Opinion: anticipating change in drug development: the emerging era of translational medicine and therapeutics. Nat. Rev. Drug Discov. 4, $815-818$.

Funk, C. D. (2001). Prostaglandins and leukotrienes: advances in eicosanoid biology. Science 294, 1871-1875.

García Rodríguez, L. A., Tacconelli, S., and Patrignani, P. (2008). Role of dose potency in the prediction of risk of myocardial infarction associated with nonsteroidal anti-inflammatory drugs in the general population. J. Am. Coll. Cardiol. 52, 1628-1636.

Gijón, M. A., Zarini, S., and Murphy, R. C. (2007). Biosynthesis of eicosanoids and transcellular metabolism of leukotrienes in murine bone marrow cells. J. Lipid Res. 48, 716-725.

Gilroy, D. W., Lawrence, T., Perretti, M., and Rossi, A. G. (2004). Inflammatory resolution: new opportunities for drug discovery. Nat. Rev. Drug Discov. 3, 401-416.

Grosser, T., Fries, S., and FitzGerald, G. A. (2006). Biological basis for the cardiovascular consequences of COX-2 inhibition: therapeutic challenges and opportunities. J. Clin. Invest. 116, 4-15.

Hanaka, H., Pawelzik, S. C., Johnsen, J. I., Rakonjac, M., Terawaki, K., Rasmuson, A., Sveinbjörnsson, B., Schumacher, M. C., Hamberg, M., Samuelsson, B., Jakobsson, P. J., Kogner, P., and Rådmark, O. (2009). Microsomal prostaglandin E synthase 1 determines tumor growth in vivo of prostate and lung cancer cells. Proc. Natl. Acad. Sci. U.S.A. 106, 18757-11862.

Houghton, J., Stoicov, C., Nomura, S., Rogers, A. B., Carlson, J., Li, H., Cai, X., Fox, J. G., Goldenring, J. R., and Wang, T. C. (2004). Gastric cancer originating from bone marrow-derived cells. Science 306, 1568-1571.

Itzkowitz, S. H., and Yio, X. (2004). Inflammation and Cancer IV. Colorectal cancer in inflammatory bowel disease: the role of inflammation. Am. J. Physiol. Gastrointest. Liver Physiol. 287, G7-G17.

Jing, Q., Huang, S., Guth, S., Zarubin, T., Motoyama, A., Chen, J., Di Padova, F., Lin, S. C., Gram, H., and Han, J. (2005). Involvement of microRNA in AU-rich element- mediated mRNA instability. Cell 120, 623-634.

Kamei, D., Murakami, M., Nakatani, Y., Ishikawa, Y., Ishii, T., and Kudo, I. (2003). Potential role of microsomal prostaglandin E synthase-1 in tumorigenesis. J. Biol. Chem. 278, 19396-19405.

Koeberle, A., Rossi, A., Zettl, H., Pergola, C., Dehm, F., Bauer, J., Greiner, C., Reckel, S., Hoernig, C., Northoff, H., Bernhard, F., Dötsch, V., Sautebin, L., Schubert-Zsilavecz, M., and Werz, O. (2010). 
The Molecular Pharmacology and in vivo Activity of 2-(4-Chloro-6-(2,3-dimethylphenylamino) pyrimidin-2-ylthio)- octanoic acid (YS121), a Dual Inhibitor of Microsomal Prostaglandin E2 Synthase-1 and 5-Lipoxygenase. J. Pharmacol. Exp. Ther. 332, 840-848.

Koeberle, A., Zettl, H., Greiner, C., Wurglics, M., SchubertZsilavecz, M., and Werz, O. (2008). Pirinixic acid derivatives as novel dual inhibitors of microsomal prostaglandin E2 synthase-1 and 5-lipoxygenase. J. Med. Chem. 51, 8068-8076.

Kudo, I., and Murakami, M. (2005). Prostaglandin E synthase: a terminal enzyme for prostaglandin E2 biosynthesis. J. Biochem. Mol. Biol. 38, 633-638.

Kulkarni, S. K., and Singh, V. P. (2007). Licofelone-a novel analgesic and anti-inflammatory agent. Curr. Top. Med. Chem. 7, 251-263.

Logan, C. M., Giordano, A., Puca, A., and Cassone, M. (2007). Prostaglandin E2: at the crossroads between stem cell development, inflammation and cancer. Cancer Biol. Ther. 6, 1517-1520.

Maini, R. N., and Taylor, P. C. (2000). Anti-cytokine therapy for rheumatoid arthritis. Annu. Rev. Med. 51, 207-229.

Massó González, E. L., Patrignani, P., Tacconelli, S., and García Rodríguez, L. A. (2010). Variability of risk of upper gastrointestinal bleeding among nonsteroidal anti-inflammatory Drugs. Arthritis Rheum. in press.

Mezhybovska, M., Wikström, K., Ohd, J. F., and Sjölander, A. (2006). The inflammatory mediator leukotriene $\mathrm{D} 4$ induces beta-catenin signaling and its association with antiapoptotic $\mathrm{Bcl}-2$ in intestinal epithelial cells. J. Biol. Chem. 281, 6776-6784.
Narumiya, S., and FitzGerald, G. A. (2001). Genetic and pharmacological analysis of prostanoid receptor function. J. Clin. Invest. 108, 25-30.

Nathan, C. (2002). Points of control in inflammation. Nature 420, 846-852.

North, T. E., Goessling, W., Walkley, C. R., Lengerke, C., Kopani, K. R., Lord, A. M., Weber, G. J., Bowman, T.V., Jang, I. H., Grosser, T., Fitzgerald, G. A., Daley, G. Q., Orkin, S. H., and Zon, L. I. (2007). Prostaglandin E2 regulates vertebrate haematopoietic stem cell homeostasis. Nature 447, 1007-1011.

Patrignani, P., Capone, M. L., and Tacconelli, S. (2008). NSAIDs and cardiovascular disease. Heart 94, 395-397.

Ranjit, N., Diez-Roux, A. V., Shea, S., Cushman, M., $\mathrm{Ni}, \mathrm{H}$., and Seeman, T. (2007). Socioeconomic position, race/ethnicity, and inflammation in the multi-ethnic study of atherosclerosis. Circulation $116,2383-2390$.

Rosen, A., and Casciola-Rosen, L. (2006). Stem cells in inflammatory disease. Curr. Opin. Rheumatol. 18, 618-619.

Siddappa, R., Martens, A., Doorn, J., Leusink, A., Olivo, C., Licht, R., van Rijn, L., Gaspar, C., Fodde, R., Janssen, F., van Blitterswijk, C., and de Boer, J. (2008). cAMP/PKA pathway activation in human mesenchymal stem cells in vitro results in robust bone formation in vivo. Proc. Natl. Acad. Sci. U.S.A. 105, 7281-7286.

Taganov, K. D., Boldin, M. P., Chang, K.-J., and Baltimore, D. (2006). NF-(B-dependent induction of microRNA miR-146, an inhibitor targeted to signaling proteins of innate immune responses. Proc. Natl. Acad. Sci. U.S.A. 103, 12481-12486.
Thun, M. J., Henley, S. J., and Patrono, C. (2002). Nonsteroidal anti-inflammatory drugs as anticancer agents: mechanistic, pharmacologic, and clinical issues. J. Natl. Cancer Inst. 94, 252-266.

Wang, D., and Dubois, R. N. (2006). Prostaglandins and cancer. Gut 55, 115-122.

Wang, M., Song, W. L., Cheng, Y., and Fitzgerald, G. A. (2008). Microsomal prostaglandin E synthase-1 inhibition in cardiovascular inflammatory disease. J. Intern. Med. 263, 500-505.

Wang, M., Zukas, A. M., Hui, Y., Ricciotti, E., Puré, E., and Fitzgerald, G. A. (2006). Deletion of microsomal prostaglandin E synthase-1 augments prostacyclin and retards atherogenesis. Proc. Natl. Acad. Sci. U.S.A. 103, 14507-14512.

Yu, Y., and Chadee, K. (1998). Prostaglandin E2 stimulates IL-8 gene expression in human colonic epithelial cells by a posttranscriptional mechanism. J. Immunol. 161, 3746-3752.

Received: 24 February 2010; accepted: 26 February 2010; published: 06 May 2010.

Citation: Patrignani P, Tacconelli S and Bruno A (2010) Grand challenges in pharmacotherapy of inflammation for the first decades of the 21st century. Front. Pharmacol. 1:2. doi: 10.3389/fphar.2010.00002

This article was submitted to Frontiers in Inflammation Pharmacology, a specialty of Frontiers in Pharmacology. Copyright $\odot 2010$ Patrignani, Tacconelli and Bruno. This is an open-access publication subject to an exclusive license agreement between the authors and the Frontiers Research Foundation, which permits unrestricted use, distribution, and reproduction in any medium, provided the original authors and source are credited. 